\title{
Preparation of PLA/chitosan nanoscaffolds containing cod liver oil and experimental diabetic wound healing in male rats study
}

\author{
Payam Khazaeli ${ }^{1,2}$, Maryam Alaei ${ }^{3}$, Mohammad Khaksarihadad ${ }^{4}$ and Mehdi Ranjbar ${ }^{1 *}$ (i)
}

\begin{abstract}
Diabetes mellitus is one of the most common metabolic disorders. One of the important metabolic complications in diabetes is diabetic foot ulcer syndrome, which causes delayed and abnormal healing of the wound. The formulation of nanoscaffolds containing cod liver oil by altering the hemodynamic balance toward the vasodilators state, increasing wound blood supply, and altering plasma membrane properties, namely altering the membrane phospholipids composition, can be effective in wound healing. In this study, electrospinning method was used to produce poly lactic acid/chitosan nanoscaffolds as a suitable bio-substitute. After preparing the nanoscaffolds, the products were characterized with dynamic light scattering (DLS), transmission electron microscopy (TEM) and scanning electron microscopy (SEM). Also optical properties of polymer and comparison between adsorption between single polymer and polymer-drug calculated with UV-Vis spectra. The structure and functional groups of the final products were characterized by Fourier-transform infrared spectroscopy (FT-IR) and energy dispersive spectroscopy (EDAX) as elemental analysis. The results showed that the optimum formulation of cod liver oil was 30\%, which formed a very thin fiber that rapidly absorbed to the wound and produced significant healing effects. According to the results, poly lactic acid/chitosan nanoscaffolds containing cod liver oil can be a suitable bio-product to be used in treating the diabetic foot ulcer syndrome.
\end{abstract}

Keywords: Poly lactic acid/chitosan nanoscaffolds, Cod liver oil, Electrospinning, Diabetic foot ulcer

\section{Research highlights}

a. Poly lactic acid/chitosan nanoscaffolds were synthesized using microwave-assisted electrospinning process.

b. Nanoscaffolds showed high potential in wound healing recovery after 14 days.

c. PLA/chitosan nanoscaffolds containing $30 \%$ cod liver oil were synthesized with the size of about $50-150 \mathrm{~nm}$.

\footnotetext{
*Correspondence: Mehdi.Ranjbar@Kmu.ac.ir

${ }^{1}$ Pharmaceutics Research Center, Institute of Neuropharmacology,

Kerman University of Medical Sciences, P.O. Box: 76175-493,

Kerman 76169-11319, Iran

Full list of author information is available at the end of the article
}

d. Wound area indicated that there was significant improvement in wound surface on the 14th day.

\section{Introduction}

The global prevalence of diabetes has increased dramatically over the past 2 decades [1]. Diabetes mellitus is the most common heterogeneous metabolic disorder [2], which is associated with a disorder in the metabolism of sugars, lipids, and proteins and is characterized by elevated blood glucose or insulin response to tissues $[3,4]$. Patients suffering from diabetes mellitus have limited ability to stimulate the immune response and are very susceptible to infection and at the risk of terminal limb amputation and recurrence of the wound [5]. Fatty

(c) The Author(s) 2020. This article is licensed under a Creative Commons Attribution 4.0 International License, which permits use, sharing, adaptation, distribution and reproduction in any medium or format, as long as you give appropriate credit to the original author(s) and the source, provide a link to the Creative Commons licence, and indicate if changes were made. The images or other third party material in this article are included in the article's Creative Commons licence, unless indicated otherwise in a credit line to the material. If material is not included in the article's Creative Commons licence and your intended use is not permitted by statutory regulation or exceeds the permitted use, you will need to obtain permission directly from the copyright holder. To view a copy of this licence, visit http://creativeco mmons.org/licenses/by/4.0/. The Creative Commons Public Domain Dedication waiver (http://creativecommons.org/publicdomain/ zero/1.0/) applies to the data made available in this article, unless otherwise stated in a credit line to the data. 
acids have physiological and pathological roles in diseases such as atherosclerosis [6, 7], inflammation [8], or normal wound healing $[9,10]$, The effect of fatty acids on wound healing is through alterations in plasma membrane properties [11, 12], such as changes in membrane phospholipids composition [13-15], increased growth factor activity [16, 17], cell differentiation [18, 19], decreased eicosanoids production [20], and lipid mediators of inflammation [21], followed by reducing inflammation and producing interleukin-1 and collagen [22]. The cod liver oil as a rich source of omega- 3 fatty acids has many potential effects on modulating various diseases, especially diabetes mellitus [23, 24], improvements in vasodilator property [25-27]. In many studies immune and allergic responses of rats was investigated for wound healing [28-30] Many scientific works have shown which cod liver oil accelerates many of the potential mechanisms involved in wound healing [31-33]. In recent years, new drug delivery systems such as nanofibers [34], nanoparticles [35], cell therapy, and stem cell [36] being used as alternative therapies for common pharmaceutical methods, which could reduce the need for continuous follow-up of the disease and increase the quality of treatment, have received great attention [37]. Nanotechnology has solved many concerns in the field of medicine due to dealing with materials that have unique properties on their surface [38-43]. Chitosan structures have a good crosslink structure for encapsulating drugs [44] and polylactic acid possesses properties such as the ability to form hydrogels in physiological conditions [45], mild gel degradation for a wound to heal successfully, and the growth and movement of nutrients [46]. In recent years, the science of nanotechnology has attracted particular attention from researchers in various fields of medicine and pharmaceuticals [47]. Nanofibers and nanoparticles can release the drug in a controlled approach for a long time [48]. These structures can act as an appropriate topical drug delivery system that can provide the appropriate drug concentration and other advantages of this system include the ability to transport hydrophilic and lipophilic drugs simultaneously depending on their structure [49].
Examples of natural polymers used in the fabrication of nanofibers with electrospinning method [50-53] include creatine [54], gelatin [55], cellulose [56], and polysaccharides such as chitosan and alginate. The synthesis of the PLA/ Chitosan nanofibers has been reviewed in recent studies [57-59]. Microwave irradiation as a cost-effective, eco-friendly, and high efficiency method is used for preparing nanoparticles for various applications [60], electrospinning process with high-voltage power, generate polymer fibers in nanometer dimensions which show unique physical and chemical properties [61]. In this study, new developments in the fabrication of nanoscaffold materials such as the microwave-assisted electrospinning process were applied to prepare and formulate poly lactic acid/chitosan containing cod liver oil as a suitable cost-effective method. Summary of the research on nanoscaffolds applications in wound healing recovery is displayed in Table 1 . The results indicate that the synergistic effect quantity of the poly lactic acid/chitosan containing hydrogel is the key factor in obtaining suitable biological wound for wound dressing.

\section{Experimental}

All materials and precursors used in this research work were pure without any impurities and were purchased directly from reputable commercial centers. Chitosan (CAS: 9012-76-4, MW Mol wt: 50,000 daltons based on

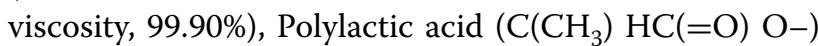
and Dimethylformamide (DMF, MW; $73.095 \mathrm{~g} \mathrm{~mol}^{-1}$ ) were purchased from Sigma Aldrich agents in IRAN). Polysorbate 80 (tween $80, \mathrm{C}_{64} \mathrm{H}_{124} \mathrm{O}_{26}$, MW: $1.310 \mathrm{~g} /$ mol) was purchased from FLOKA company in Switzerland. $\mathrm{NaOH}$ (d: $2.13 \mathrm{~g} / \mathrm{ml}, \mathrm{MW}: 39.9971 \mathrm{~g} / \mathrm{mol}, 99.99 \%)$ was purchased from Dr. Abidi company in IRAN. We purchased cod oil lever from institute of pharmaceutical services Razavi company. Xylazine and Ketamine for anesthesia and intraperitoneal tolerance in rats were purchased from Alfasan group of companies in Netherlands. Male rats were obtained from Kerman university of medical animal's farm. Also this study received ethical approval from the local ethical committee of the kerman

Table 1 Summary of researches about nanoscaffolds applications in wound healing recovery

\begin{tabular}{|c|c|c|c|c|}
\hline Types of nanofibers & Particle size (nm) & Synthesis method & Characterization & References \\
\hline PVA-clay nanocomposite & $60-100$ & Cyclic freezing-thawing & SEM, XRD, tensile modulus & {$[63]$} \\
\hline Chitosan & $20-40$ & Coprecipitation & FTIR, TGA, DSC, SEM and TEM & [64] \\
\hline $\begin{array}{l}\text { Cerium oxide nanoparticle-containing } \\
\text { poly ( } \varepsilon \text {-caprolactone) }\end{array}$ & 50 & Electrospinning & SEM, DLS, MTT & {$[65]$} \\
\hline Halloysite and chitosan oligosaccharide & 200 & Composition & SEM, EDX, UHRTEM, Zeta potential In vivo & {$[66]$} \\
\hline Montmorillonite/chitosan & - & Solid state & HRTEM, XRD, XEDS, TGA & [67] \\
\hline
\end{tabular}




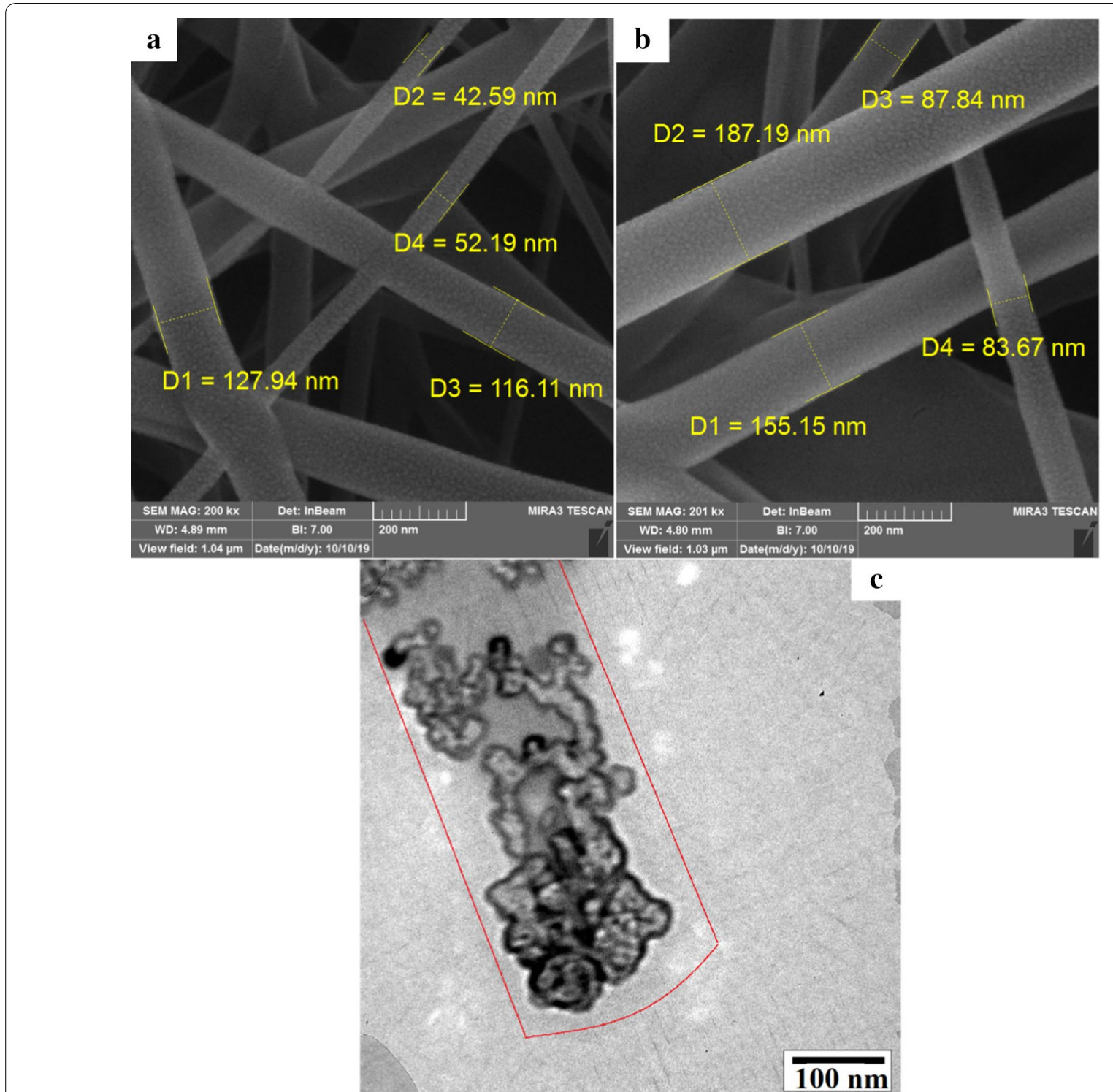

Fig. 1 SEM images of the poly lactic acid/chitosan nanofibers containing cod liver oil 30\% w/w cod liver oil (a), 15\% w/w cod liver oil (b) and TEM image of the poly lactic acid/chitosan nanofibers containing $30 \% \mathrm{w} / \mathrm{w}$ cod liver oil

university of medical sciences as a thesis research at the faculty of pharmacy kerman university of medical sciences with number 1124. Male rat weighing 150-200 g was fed with standard diet and kept under 12:12 h light/ dark cycles, at $20{ }^{\circ} \mathrm{C}$ and relative humidity of $25-30 \%$. XRD patterns for crystalline phase detection were recorded by a Rigaku D-max C III, X-ray diffractometer using Ni-filtered $\mathrm{Cu}$ Ka radiation. Microscopic morphology and investigation of surface propertieso of the products were characterized by SEM (LEO 1455VP). The energy dispersive spectrometry (EDS) supplier analysis to determine the elements in the samples was studied by
XL30. Transmission electron microscopy (TEM) images were obtained with a Philips EM208 transmission electron microscope with an accelerating voltage of $200 \mathrm{kV}$. Fourier transform infrared (FT-IR) spectra were recorded on Shimadzu Varian 4300 spectrophotometer in $\mathrm{KBr}$ pellets. To absorption evaluate samples ultraviolet-visible spectroscopy analysis was carried out using Shimadzu UV-2600 UV-Vis spectrophotometer.

\section{Preparing PLA/chitosan nanofibers}

To prepare the polymer phase, at first, $0.2 \mathrm{~g}$ of PLA was dissolved in 18:3 $\mathrm{ml}$ ratio of deionized water and 

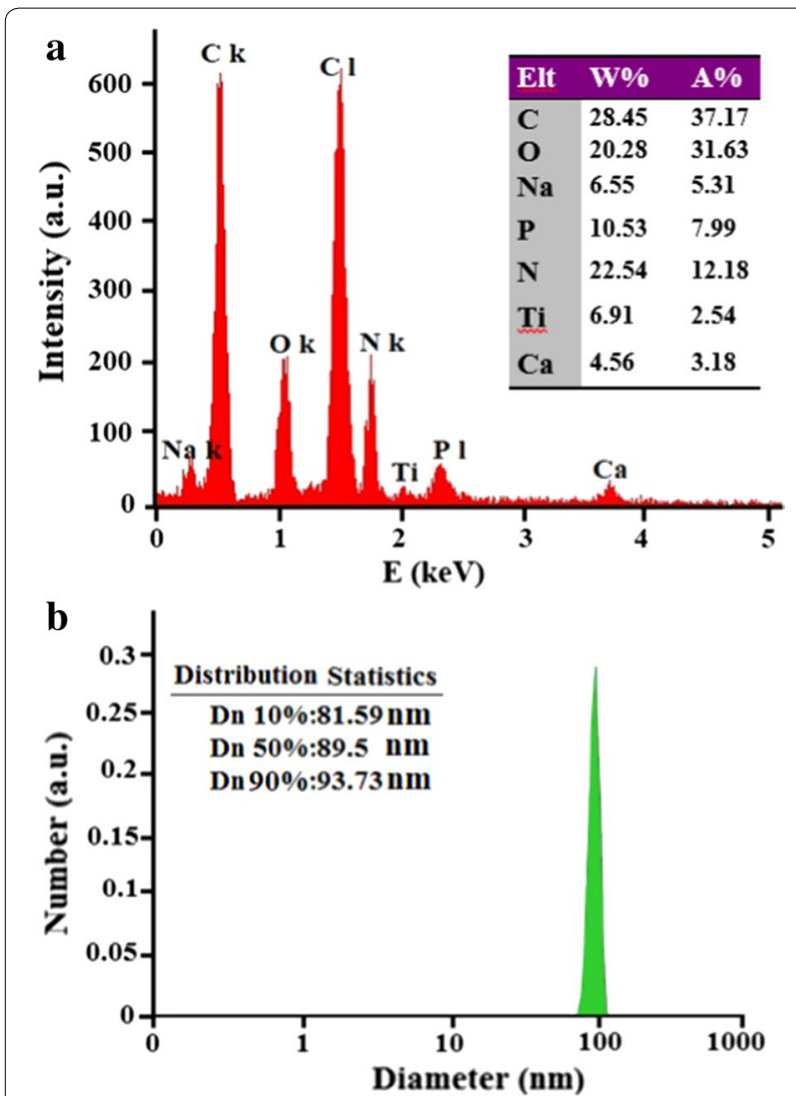

Fig. 2 EDAX supplier analysis (a) and DLS data diagram after 15 min ultrasonic irradiation at $60 \mathrm{~W}$ (b) of the poly lactic acid/chitosan nanofibers $30 \%$ w/w containing cod liver oil

ethanol after heating and stirring at $50{ }^{\circ} \mathrm{C}$ and RPM 400 for $45 \mathrm{~min}$. Then, $5 \mathrm{ml}$ of $\mathrm{NaOH}(2 \mathrm{~mol} / \mathrm{l})$ was added to the above solution and this solution was heated at $60{ }^{\circ} \mathrm{C}$ and stirred for $30 \mathrm{~min}$. In the next step, $0.05 \mathrm{~g}$ of chitosan was dissolved in 2:1 ml ratio of deionized water and dimethylformamide after $110 \mathrm{~min}$. Subsequently, the solutions were transferred to a beaker and exposed to the microwave irradiation oven under the power of $450 \mathrm{~W}$ for $5 \mathrm{~min}$. Regular cycles of the microwave irradiation were set to $30 \mathrm{~s}$ off and $60 \mathrm{~s}$ on. Finally, the solutions were placed in an environment free of contamination for $24 \mathrm{~h}$ to complete the crystallization process.

\section{Cod liver oil loading}

First, $2 \mathrm{ml}$ of polymeric solution was added to $100 \mu \mathrm{l}$ of the drug with the concentrations of $15 \%$ and $30 \%$ by weight in the presence of $350 \mu \mathrm{l}$ Tween as the surfactant agent and placed on the reflux system for $30 \mathrm{~min}$ at $50{ }^{\circ} \mathrm{C}$ and $500 \mathrm{rpm}$ on the shaker for $15 \mathrm{~min}$. PLA/chitosan nanoscaffolds containing cod liver oil were formed by an electrospinning device. Nanoscaffolds containing $30 \% \mathrm{w} / \mathrm{w}$ and $15 \% \mathrm{w} / \mathrm{w}$ cod liver oil were prepared at the

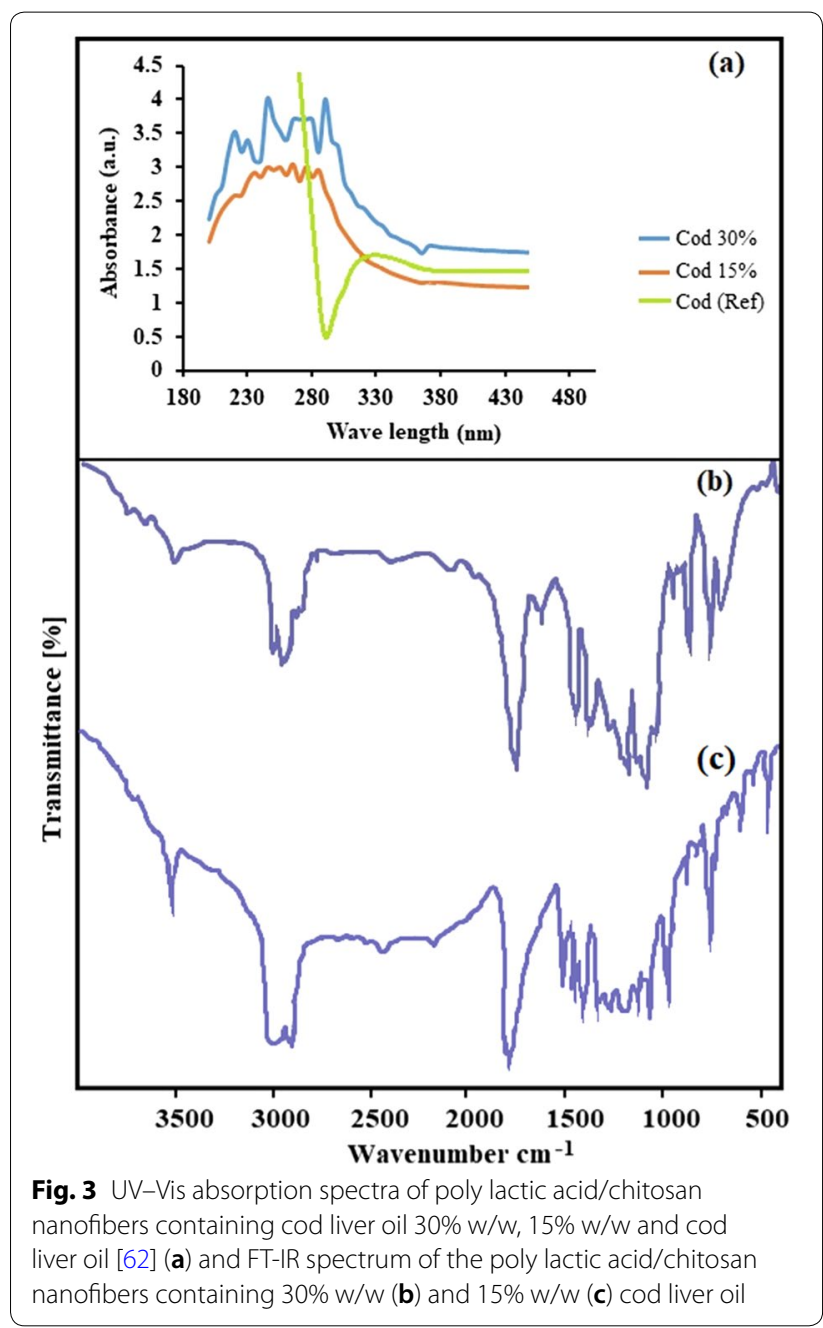

speed of $2 \mathrm{ml} / \mathrm{h} ; 12.1 \mathrm{~V}$ and jet rotation speed of $100 \mathrm{rpm}$ were used to form the nanofibers.

\section{In vivo study}

For the in vivo study, the male rats were divided into four groups (each group containing 6 mice weighing approximately $200 \mathrm{~g}$ ). Animals were diabetic by the intraperitoneal injection of $60 \mathrm{mg} / \mathrm{kg}$ and their diabetes

Table 2 Evaluation of wound healing rate in study groups studied on days 7 and 14

\begin{tabular}{lll}
\hline Percentage of recovery per day & Seven & Fourteenth \\
\hline Control group & 23.5 & 42.0 \\
Nanofiber + cod liver oil 30\% & 64.8 & 94.5 \\
Nanofiber + cod liver oil 15\% & 53.5 & 86.0 \\
Poly lactic acid/chitosan nanofibers & 34.1 & 60.0 \\
Drug soluble group & 39.5 & 59.9 \\
\hline
\end{tabular}


was confirmed after 3 days by measuring glucose using a glucometer. Then, after anesthetizing the rats with ketamine/xylazine, an ulcer about $1.5 \mathrm{~cm}$ in the area between the two scapula was created by punch biopsy and, then, the drug was positioned topically on each group. For this study, four groups of mice were divided into the following groups: Mice in Group 1 treated with nanofiber alone; Mice in Group 2 treated with cod oil only; Mice in Group 3 treated with nanofiber delivery system containing cod liver oil for wound healing; and Mice in Group 4 received no treatment (negative control). To induce diabetes, we injected strepotozocin $60 \mathrm{mg} / \mathrm{kg}$ intraperitoneally in rats. All the experimental procedures were carried out according to the protocols set for working with animals at Kerman University of Medical Science (Kerman, Iran).

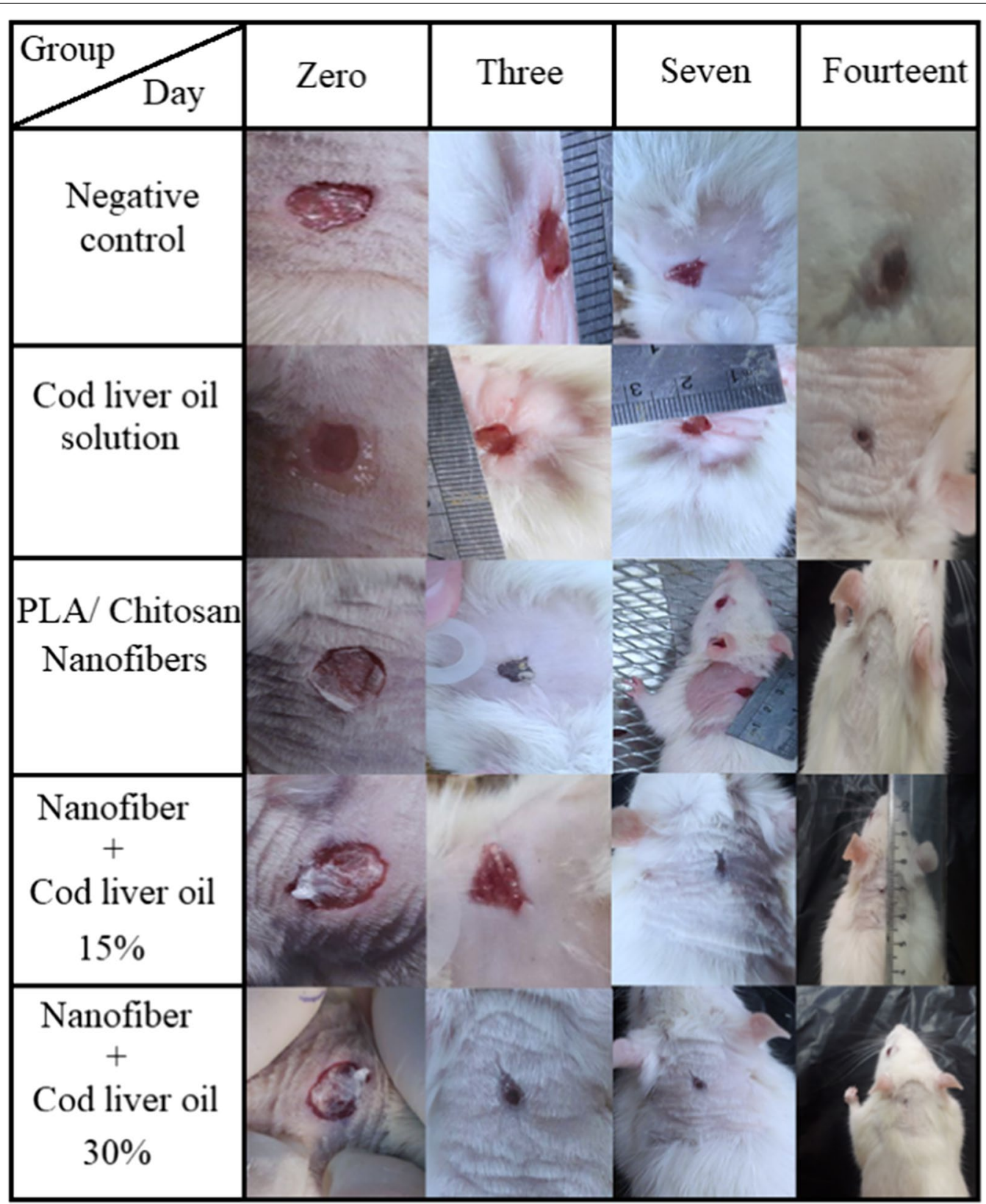

Fig. 4 Wound area in five groups of animals studied on days $0,3,7$ and 14 (mean $\pm s d ; N=3$ ) 


\section{Result and discussion}

\section{Physicochemical characteristics}

Morphological properties and surface features of the nanofibers were observed through scanning electron microscopy (SEM) images. SEM images with the approximate scaffold size of poly lactic acid/chitosan nanofibers containing $30 \%$ and $15 \%$ cod liver oil are displayed in Fig. 1a and b, respectively. As can be seen from the SEM images of the nanoscaffold structures, they were uniform and had no cracking along the formation. The nanoscaffold structures encapsulated different concentrations of cod liver oil without any systemic defects and the nanofibers containing $30 \%$ cod liver oil showed less diameter than $15 \%$ cod liver oil; this may be due to higher solubility of the polymer phase at higher concentrations of oil phase. According to SEM images, the average size of the diameter scaffold tube was estimated between about 50 and $150 \mathrm{~nm}$. To investigate the three-dimensional (3D) images of the fibers, we did transmission electron microscopy (TEM). According to the TEM images, the cod liver oil was trapped uniformly in the spaces between PLA/chitosan nanoscaffolds. The oil phase ranges in the polymer phase were well-defined. The TEM image of $30 \%$ $\mathrm{w} / \mathrm{w}$ cod liver oil cod liver oil distributed in poly lactic acid/chitosan nanoscaffolds is shown in Fig. 1c.

Energy dispersive spectroscopy (EDAX) is a suitable supplier analysis used for the semi-quantitative analysis of elements. This method is mainly used to obtain point chemical composition and quantitatively investigate the poly lactic acid/chitosan nanoscaffolds containing cod liver oil. About 37.17 percent of the total atomic weight of the final products was related to $\mathrm{C}$ atoms; this could be related to carbon atoms in poly lactic acid, chitosan, omega3 in cod liver oil, and Tween structures. The existence of the $\mathrm{O}, \mathrm{Na}$, and $\mathrm{N}$ atoms to the amount of about $31.63,5.31$, and 15.36 percent could be related to the existence of these atoms in poly lactic acid, chitosan, cod liver oil, Tween, $\mathrm{NaOH}$, and dimethylformamide structures. The small amounts of $\mathrm{Ti}$ and $\mathrm{Ca}$ atoms could be related to the unpredictable impurities in the final products. The EDAX as a supplier analysis of the poly lactic acid/chitosan nanoscaffolds containing 30\% cod liver oil is shown in Fig. 2a. The size distribution obtained from the nanoscaffolds was a plot of the relative intensity of light scattered by nanoscaffolds in various size classes and introduced as the intensity size distribution. Results related to the size distribution of the nanoscaffolds obtained from dynamic light scattering analysis showed good match with SEM images and estimated the size of the poly lactic acid/chitosan nanoscaffolds containing 30\% cod liver after $15 \mathrm{~min}$ ultrasonic irradiation at $60 \mathrm{~W}$ fibers of about $50-150 \mathrm{~nm}$ in Fig. 2b. Also the size distribution of PLA/chitosan nanofibers without cod oil liver was calculated about $120 \mathrm{~nm}$.

$\mathrm{UV}-\mathrm{Vis}$ as a general qualitative technique can be used to identify and confirm functional groups in a compound by matching the absorbance spectrum. Absorption in UV-Vis spectroscopy follows the Beer's Law:

$$
\mathrm{A}=\varepsilon \times \mathrm{b} \times \mathrm{C} \text {. }
$$

where $\varepsilon$ is the molar attenuation coefficient, $\mathrm{b}$ is path length, and $\mathrm{C}$ is concentration. UV-Vis absorption spectra of poly lactic acid/chitosan nanoscaffolds containing cod liver oil showed that, with increasing concentration from 15 to $30 \% \mathrm{w} / \mathrm{w}$, absorbent peaks became noticeably more intense. However, the cod liver oil was not absorbed alone and it can be concluded that more loading of cod liver oil occurred in poly lactic acid/chitosan nanoscaffolds. Figure 3a demonstrates UV-vis absorption spectra of poly lactic acid/chitosan nanofibers containing cod liver oil of $30 \% \mathrm{w} / \mathrm{w}$ and $15 \% \mathrm{w} / \mathrm{w}$ compared with the cod liver oil [62]. Fourier transform infrared spectroscopy (FT-IR) is an analytical technique used to identify functional groups in materials. Figure $3 \mathrm{~b}, \mathrm{c}$ shows FT-IR spectrum of the prepared poly lactic acid/ chitosan nanoscaffolds containing $30 \% \mathrm{w} / \mathrm{w}$ and $15 \%$ $\mathrm{w} / \mathrm{w}$ cod liver oil in the region $400-4000 \mathrm{~cm}^{-1}$, respectively. The absorption peaks at $3454 \mathrm{~cm}^{-1}$ and $1630 \mathrm{~cm}^{-1}$ regions could be attributed to the stretching and bending vibrations of $\mathrm{O}-\mathrm{H}$ groups from chitosan and omega3 structures in the cod liver oil. The obtained peaks at $2884 \mathrm{~cm}^{-1}, 1650 \mathrm{~cm}^{-1}$, and $1600 \mathrm{~cm}^{-1}$ expressed the existence of stretching mode $\mathrm{C}-\mathrm{H}, \mathrm{CH}_{2}$ groups, $\mathrm{C}=\mathrm{O}$, $\mathrm{C}=\mathrm{C}$, and $\mathrm{C}-\mathrm{N}$ regions in chitosan omega 3 in cod liver oil and poly lactic acid structures. The reflectance at $3093 \mathrm{~cm}^{-1}$ showed $\mathrm{N}-\mathrm{H}$ band in chitosan. In general, the cod liver oil structures with forming chemical bonds are located in nanobio-polymeric nanoscaffold structures.

\section{In vivo study}

Diabetic rats were evaluated in two ways; (a) blood glucose measurement by glucometer, rats with blood glucose above $200 \mathrm{mg} / \mathrm{dl}$ were considered diabetic and selected for further study, (b) the selected rats were examined for the appearance of diabetic symptoms including polyuria, overeating, and thirst and were assured of their diabetic status. As shown in the results and tables, in the group using nanofibers mixed with cod liver oil, the wound healing process (assessed by measuring the wound area) was investigated. It showed significantly better results than the group that used nanofiber alone or cod liver oil alone. It also appears that $30 \%$ cod liver oil supplementation with polyelactic acid/chitosan nanoscaffolds resulted in $94.5 \%$ 


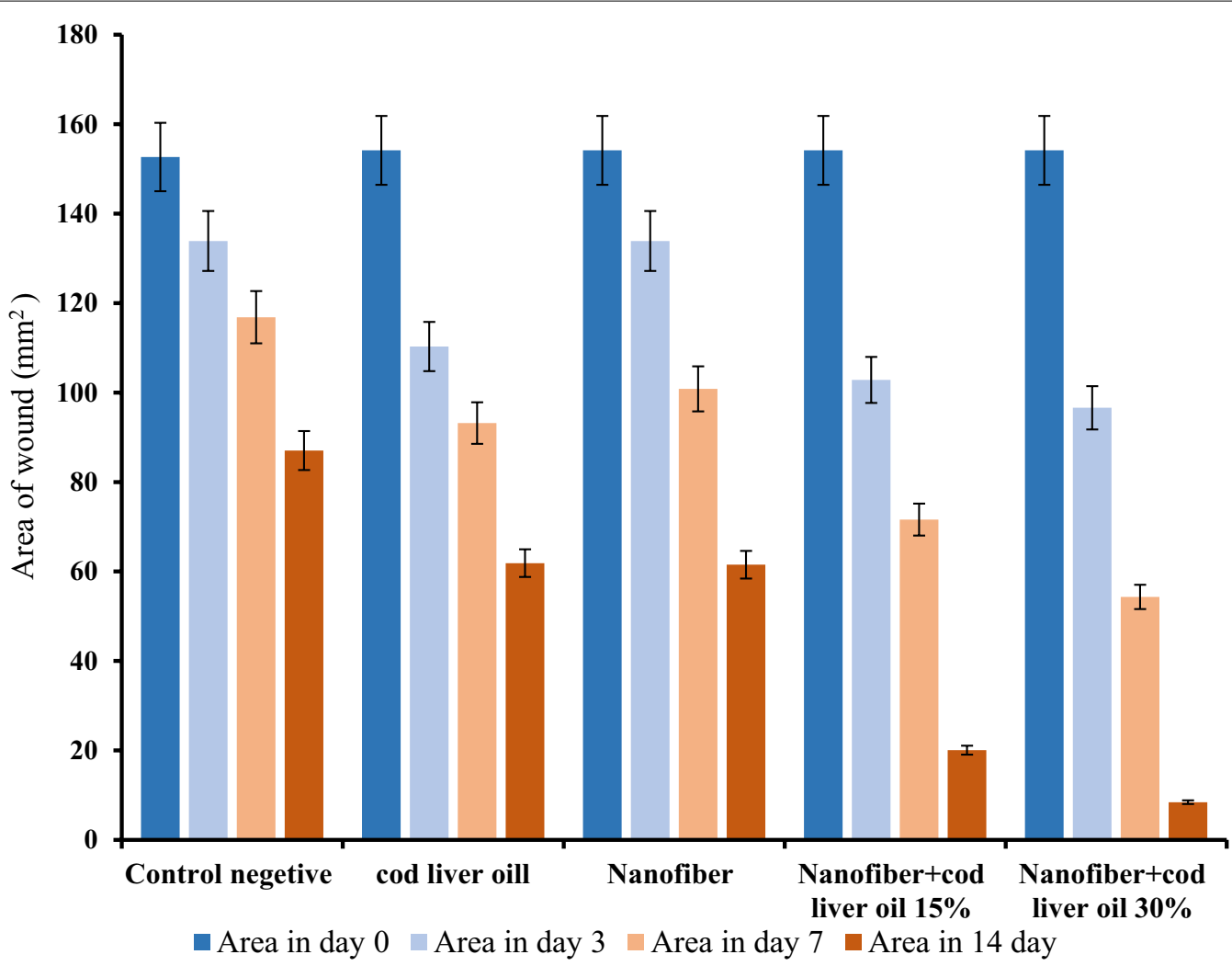

Fig. 5 The wound healing process observed in the study groups

wound healing on day 14 , whereas $15 \%$ cod liver oil can heal wounds by about $86 \%$ on day 14 , as presented in Table 2. Macroscopic changes of the wound were evaluated for treatment progress on days $0,3,7$, and 14 after treatment and recorded by a photograph. The percentage of wound healing was calculated using the following formula: used, the coating swelled after the absorption of moisture and created a very small gap between the coating and the wound surface. On day 14, these characteristics were well observed and the nanoscaffold porosity property permitted oxygen to pass through the wound while keeping its surface moist.

Wound area in five groups of animals studied on days

Percentage of recovery $=($ Surface wound on the first day - Surface wound in day X $) /($ Surface wound on the first day $) \times 100$.

Figure 4 demonstrates a 14-day course examination of the wound surface and a photograph of the wound healing process. On days $0,3,7$, and 14 , the rate of wound healing in the nanoscaffold saline-treated mice with $30 \%$ cod oil was significantly different from that of the untreated control group and also from the other groups. The poly lactic acid/chitosan nanoscaffolds as bio-compatible and bio-degradable polymers could interact with skin cells and accelerate the healing process. Due to the high porosity of the nanoscaffold coating and the hydrogel-like properties of the polymers
$0,3,7$, and 14 (mean \pm sd; $N=3$ ) is shown in Fig. 5. The area of the wound in the group with $30 \%$ cod oil was significantly less than the other groups; this indicated greater improvement in this group than in the other groups. The presence of bio-compatible nanofibers not only induced immune and allergic responses, but also made the body resemble the original tissue located in the wound. As a result, bio-chemical signals are needed to accelerate recovery and, eventually, wound healing will occur faster. 


\section{Conclusion}

In this research, the nanofibers scaffolding produced with electrospinning method was used to repair wounds on the skin of the rats. Macroscopic and microscopic studies were performed on the wounds to determine the efficacy of the produced nanoscaffolds after the desired time. The poly lactic acid/chitosan as biocompatible and bio-degradable polymers scaffolding were designed for wound healing to be able to control drug (cod liver oil) release over a long period of time by improving the chemical structure. The poly lactic acid/chitosan nanoscaffolds containing 30\% cod liver oil showed more healing and less wound area on day 14; this can be due to permeability and sufficient oxygen for tissue repair. Moisture retention of the wound medium for accelerating its healing, color change, and $\mathrm{pH}$ changes to keep the wound site safe from bacteria, contamination, and non-contamination was among the characteristics of the produced nanoscaffold.

\section{Acknowledgements}

Authors are grateful to council of Pharmaceutics Research Center, Institute of Neuropharmacology, Kerman University of Medical Sciences, Kerman, Iran.

\section{Authors' contributions}

PK: wrote the manuscript, supervised the research. MA: Designed and performed experiments. MK: Conceived and planned the experiments. MR: Developed the theoretical formalism, performed the analytic calculations. All authors read and approved the final manuscript.

\section{Competing interests}

The authors declare that they have no competing interests.

\author{
Author details \\ 1 Pharmaceutics Research Center, Institute of Neuropharmacology, Kerman \\ University of Medical Sciences, P.O. Box: 76175-493, Kerman 76169-11319, Iran. \\ ${ }^{2}$ Faculty of Pharmacy, Kerman University of Medical Sciences, Kerman, Iran. \\ ${ }^{3}$ Student Research Committee, Kerman University of Medical Sciences, Ker- \\ man, Iran. ${ }^{4}$ Neuroscience Research, and Physiology Research Centers, Kerman \\ University of Medical Sciences, Kerman, Iran.
}

Received: 24 September 2020 Accepted: 20 November 2020 Published online: 30 November 2020

\section{References}

1. Wong SL, Demers M, Martinod K, Gallant M, Wang Y, Goldfine AB, et al. Diabetes primes neutrophils to undergo NETosis, which impairs wound healing. Nat Med. 2015;21(7):815.

2. Majd SA, Khorasgani MR, Moshtaghian SJ, Talebi A, Khezri M. Application of chitosan/PVA nano fiber as a potential wound dressing for streptozotocin-induced diabetic rats. Int J Biol Macromol. 2016;92:1162-8.

3. Anisha B, Biswas R, Chennazhi K, Jayakumar RJ. Chitosan-hyaluronic acid/nano silver composite sponges for drug resistant bacteria infected diabetic wounds. Int J Biol Macromol. 2013;62:310-20.

4. Zhao L, Niu L, Liang H, Tan H, Liu C, Zhu FJ, et al. pH and glucose dualresponsive injectable hydrogels with insulin and fibroblasts as bioactive dressings for diabetic wound healing. ACS Appl Mater Interfaces. 2017;9(43):37563-74.

5. Xiao J, Zhu Y, Huddleston S, Li P, Xiao B, Farha OK, et al. Copper metalorganic framework nanoparticles stabilized with folic acid improve wound healing in diabetes. ACS Nano. 2018;12(2):1023-32.
6. Spickett CM. Chlorinated lipids and fatty acids: an emerging role in pathology. Pharmacol Ther. 2007;115(3):400-9.

7. Calder PC. The role of marine omega-3 (n-3) fatty acids in inflammatory processes, atherosclerosis and plaque stability. Mol Nutr Food Res. 2012;56(7):1073-80.

8. Calder PC. Polyunsaturated fatty acids, inflammation, and immunity. Lipids. 2001;36(9):1007-24.

9. Norling LV, Spite M, Yang R, Flower RJ, Perretti M, Serhan CN. Cutting edge: humanized nano-proresolving medicines mimic inflammationresolution and enhance wound healing. J Immunol. 2011;186(10):5543-7.

10. Laroui H, Ingersoll SA, Liu HC, Baker MT, Ayyadurai S, Charania MA, et al. Dextran sodium sulfate (DSS) induces colitis in mice by forming nanolipocomplexes with medium-chain-length fatty acids in the colon. PLoS ONE. 2012;7(3):e32084

11. Baghaie S, Khorasani MT, Zarrabi A, Moshtaghian J. Wound healing properties of PVA/starch/chitosan hydrogel membranes with nano zinc oxide as antibacterial wound dressing material. J Biomater Sci Polym Ed. 2017:28(18):2220-41.

12. Siscovick DS, Raghunathan T, King I, Weinmann S, Wicklund KG, Albright J, et al. Dietary intake and cell membrane levels of long-chain n-3 polyunsaturated fatty acids and the risk of primary cardiac arrest. JAMA. 1995;274(17):1363-7.

13. Saville JT, Zhao Z, Willcox MD, Ariyavidana MA, Blanksby SJ, Mitchell TW. Identification of phospholipids in human meibum by nano-electrospray ionisation tandem mass spectrometry. Exp Eye Res. 2011;92(3):238-40.

14. Di Pasqua R, Hoskins N, Betts G, Mauriello G. Changes in membrane fatty acids composition of microbial cells induced by addiction of thymol, carvacrol, limonene, cinnamaldehyde, and eugenol in the growing media. J Agric Food Chem. 2006;54(7):2745-9.

15. Falcone DL, Ogas JP, Somerville CR. Regulation of membrane fatty acid composition by temperature in mutants of Arabidopsis with alterations in membrane lipid composition. BMC Plant Biol. 2004;4(1):17.

16. Kurosu H, Choi M, Ogawa Y, Dickson AS, Goetz R, Eliseenkova AV, et al. Tissue-specific expression of $\beta$ Klotho and fibroblast growth factor (FGF) receptor isoforms determines metabolic activity of FGF19 and FGF21. J Biol Chem. 2007;282(37):26687-95.

17. Chui PC, Antonellis PJ, Bina HA, Kharitonenkov A, Flier JS, Maratos-Flier E. Obesity is a fibroblast growth factor 21 (FGF21)-resistant state. Diabetes. 2010;59(11):2781-9.

18. Lee J-H, Tachibana $\mathrm{H}$, Morinaga $Y$, Fujimura $Y$, Yamada K. Modulation of proliferation and differentiation of $\mathrm{C}_{2} \mathrm{C}_{12}$ skeletal muscle cells by fatty acids. Life Sci. 2009;84(13-14):415-20.

19. Yanes O, Clark J, Wong DM, Patti GJ, Sanchez-Ruiz A, Benton HP, et al. Metabolic oxidation regulates embryonic stem cell differentiation. Nat Chem Biol. 2010;6(6):411-7.

20. Weaver J, Maddox J, Cao Y, Mullarky I, Sordillo L. Increased 15-HPETE production decreases prostacyclin synthase activity during oxidant stress in aortic endothelial cells. Free Radic Biol Med. 2001;30(3):299-308.

21. Bennett M, Gilroy DW. Lipid mediators in inflammation. In: Myeloid cells in health and disease: a synthesis. Washington: ASM Press; 2017. p. 343-66.

22. Franz S, Allenstein F, Kajahn J, Forstreuter I, Hintze V, Möller S, et al. Artificial extracellular matrices composed of collagen I and high-sulfated hyaluronan promote phenotypic and functional modulation of human pro-inflammatory M1 macrophages. Acta Biomater. 2013;9(3):5621-9.

23. Ward OP, Singh AJ. Omega-3/6 fatty acids: alternative sources of production. Process Biochem. 2005;40(12):3627-52.

24. Turk HF, Monk JM, Fan Y-Y, Callaway ES, Weeks B, Chapkin RS. Inhibitory effects of omega-3 fatty acids on injury-induced epidermal growth factor receptor transactivation contribute to delayed wound healing. Am J Physiol Cell Physiol. 2013;304(9):C905-17.

25. Scherhag R, Kramer HJ, Düsing R. Dietary administration of eicosapentaenoic and linolenic acid increases arterial blood pressure and suppresses vascular prostacyclin synthesis in the rat. Prostaglandins. 1982;23(3):369-82.

26. McVeigh G, Brennan G, Johnston G, McDermott B, McGrath L, Henry $W$, et al. Dietary fish oil augments nitric oxide production or release in patients with type 2 (non-insulin-dependent) diabetes mellitus. Diabetologia. 1993;36(1):33-8.

27. Codde JP, Beilin LJ. Dietary fish oil prevents dexamethasone induced hypertension in the rat. Clin Sci. 1985;69(6):691-9. 
28. Falcone FH, Zillikens D, Gibbs BF. The 21st century renaissance of the basophil? Current insights into its role in allergic responses and innate immunity. Exp Dermatol. 2006;15(11):855-64.

29. Wilgus TA. Immune cells in the healing skin wound: influential players at each stage of repair. Pharmacol Res. 2008;58(2):112-6.

30. Godbout JP, Glaser R. Stress-induced immune dysregulation: implications for wound healing, infectious disease and cancer. J Neuroimmune Pharmacol. 2006;1 (4):421-7.

31. Khanna PK, Nair CK. Synthesis of silver nanoparticles using cod liver oil (fish oil): green approach to nanotechnology. Int J Green Nanotechnol Phys Chem. 2009;1(1):P3-9.

32. Terkelsen LH, Eskild-Jensen A, Kjeldsen H, Barker JH, Vibeke Elisabeth Hjortdal A. Topical application of cod liver oil ointment accelerates wound healing: an experimental study in wounds in the ears of hairless mice. Scand J Plast Surg Hand Surg. 2000;34(1):15-20.

33. Mahmoud Ali M, Radad KJ. Cod liver oil/honey mixture: an effective treatment of equine complicated lower leg wounds. Vet World. 2011;4(7):304-10.

34. Rho KS, Jeong L, Lee G, Seo B-M, Park YJ, Hong S-D, et al. Electrospinning of collagen nanofibers: effects on the behavior of normal human keratinocytes and early-stage wound healing. Biomaterials. 2006;27(8):1452-61.

35. Tian J, Wong KK, Ho CM, Lok CN, Yu WY, Che CM, et al. Topical delivery of silver nanoparticles promotes wound healing. 2007;2(1):129-36.

36. Gauglitz GG, Jeschke MG. Combined gene and stem cell therapy for cutaneous wound healing. Mol Pharm. 2011;8(5):1471-9.

37. Öien RF, Forssell HW. Ulcer healing time and antibiotic treatment before and after the introduction of the Registry of Ulcer Treatment: an improvement project in a national quality registry in Sweden. BMJ Open. 2013;3(8):e003091.

38. Ahlawat J, Guillama Barroso G, Masoudi Asil S, Alvarado M, Armendariz I, Bernal J, et al. Nanocarriers as potential drug delivery candidates for overcoming the blood-brain barrier: challenges and possibilities. ACS Omega. 2020;5:12583-95.

39. Khatoon A, Khan F, Ahmad N, Shaikh S, Rizvi SMD, Shakil S, et al. Silver nanoparticles from leaf extract of Mentha piperita: eco-friendly synthesis and effect on acetylcholinesterase activity. Life Sci. 2018;209:430-4.

40. Sahai N, Ahmad N, Gogoi M. Nanoparticles based drug delivery for tissue regeneration using biodegradable scaffolds: a review. Curr Pathobiol Rep. 2018;6(4):219-24.

41. Ahmad N, Bhatnagar S, Ali SS, Dutta R. Phytofabrication of bioinduced silver nanoparticles for biomedical applications. Int J Nanomed. 2015;10:7019.

42. Ahmad N, Bhatnagar S, Saxena R, labal D, Ghosh A, Dutta R. Biosynthesis and characterization of gold nanoparticles: kinetics, in vitro and in vivo study. Mater Sci Eng C. 2017;78:553-64.

43. Ahmad N, Bhatnagar S, Dubey SD, Saxena R, Sharma S, Dutta R. Nanopackaging in food and electronics. In: Nanoscience in food and agriculture. Cham: Springer; 2017. p. 45-97.

44. Bernkop-Schnürch A, Dünnhaupt S. Chitosan-based drug delivery systems. Eur J Pharm. 2012;81(3):463-9.

45. Alsaheb RA, Aladdin A, Othman NZ, Malek RA, Leng OM, Aziz R, et al. Recent applications of polylactic acid in pharmaceutical medical industries. J Chem Pharm Res. 2015;7(12):51-63.

46. Narayanan G, Vernekar VN, Kuyinu EL, Laurencin CT. Poly (lactic acid)based biomaterials for orthopaedic regenerative engineering. Adv Drug Deliv Rev. 2016;107:247-76.

47. Mei L, Zhang Z, Zhao L, Huang L, Yang X-L, Tang J, et al. Pharmaceutical nanotechnology for oral delivery of anticancer drugs. Adv Drug Deliv Rev. 2013;65(6):880-90.

48. Liu M, Duan X-P, Li Y-M, Yang D-P, Long Y-Z. Electrospun nanofibers for wound healing. Mater Sci Eng. 2017;76:1413-23.
49. Fahr A, van Hoogevest P, May S, Bergstrand N, Leigh ML. Transfer of lipophilic drugs between liposomal membranes and biological interfaces: consequences for drug delivery. Eur J Pharm Sci. 2005;26(3-4):251-65.

50. Liu Y, Ren Z-F, He J-H. Bubble electrospinning method for preparation of aligned nanofibre mat. Mater Sci Technol. 2010;26(11):1309-12.

51. Bai J, Li Y, Yang S, Du J, Wang S, Zheng J, et al. A simple and effective route for the preparation of poly (vinylalcohol)(PVA) nanofibers containing gold nanoparticles by electrospinning method. Solid State Commun. 2007;141(5):292-5.

52. Dharmaraj N, Kim C, Kim K, Kim H, Suh EK. Spectral studies of $\mathrm{SnO}_{2}$ nanofibres prepared by electrospinning method. Spectrochim Acta A Mol Biomol Spectrosc. 2006;64(1):136-40.

53. Khorami HA, Keyanpour-Rad M, Vaezi MR. Synthesis of $\mathrm{SnO}_{2} / \mathrm{ZnO}$ composite nanofibers by electrospinning method and study of its ethanol sensing properties. Appl Surf Sci. 2011;257(18):7988-92.

54. Caspe $\mathrm{S}$. The role of creatine in cell growth in vitro and its use in wound healing. J lab Clin Med. 1944;29:483-5.

55. Kanokpanont S, Damrongsakkul S, Ratanavaraporn J, Aramwit P. An innovative bi-layered wound dressing made of silk and gelatin for accelerated wound healing. Int J Pharm. 2012;436(1-2):141-53.

56. Qiu Y, Qiu L, Cui J, Wei Q. Bacterial cellulose and bacterial cellulose-vaccarin membranes for wound healing. Mater Sci Eng. 2016;59:303-9.

57. Suryani AH, Wirjosentono B, Rihayat T, Salisah Z. Synthesis and characterization of poly (lactid acid)/chitosan nanocomposites based on renewable resources as biobased-material. J Phys Conf. 2018;953:012015.

58. Raza ZA, Anwar F. Fabrication of poly (lactic acid) incorporated chitosan nanocomposites for enhanced functional polyester fabric. Polímeros. 2018;28(2):120-4.

59. Jeevitha D, Amarnath K. Chitosan/PLA nanoparticles as a novel carrier for the delivery of anthraquinone: synthesis, characterization and in vitro cytotoxicity evaluation. Colloids Surf B. 2013;101:126-34.

60. Bhuvaneswari T, Thiyagarajan M, Geetha N, Venkatachalam P. Bioactive compound loaded stable silver nanoparticle synthesis from microwave irradiated aqueous extracellular leaf extracts of Naringi crenulata and its wound healing activity in experimental rat model. Acta Trop. 2014;135:55-61.

61. Jiang S, Chen Y, Duan G, Mei C, Greiner A, Agarwal S. Electrospun nanofiber reinforced composites: a review. Polym Chem. 2018;9(20):2685-720.

62. Anil Kumar K, Viswanathan K. Study of UV transmission through a few edible oils and chicken oil. J Spectrosc. 2012. https://doi. org/10.1155/2013/540417.

63. Kokabi M, Sirousazar M, Hassan ZM. PVA-clay nanocomposite hydrogels for wound dressing. Eur Polym J. 2007:43(3):773-81.

64. Archana D, Dutta J, Dutta PK. Evaluation of chitosan nano dressing for wound healing: characterization, in vitro and in vivo studies. Int J Biol Macromol. 2013;57:193-203.

65. Naseri-Nosar M, Farzamfar S, Sahrapeyma H, Ghorbani S, Bastami F, Vaez A, et al. Cerium oxide nanoparticle-containing poly ( $\varepsilon$-caprolactone)/ gelatin electrospun film as a potential wound dressing material: in vitro and in vivo evaluation. Mater Sci Eng. 2017;81:366-72.

66. Sandri G, Aguzzi C, Rossi S, Bonferoni MC, Bruni G, Boselli C, et al. Halloysite and chitosan oligosaccharide nanocomposite for wound healing. Acta Biomater. 2017;57:216-24.

67. Aguzzi C, Sandri G, Bonferoni C, Cerezo P, Rossi S, Ferrari F, et al. Solid state characterisation of silver sulfadiazine loaded on montmorillonite/ chitosan nanocomposite for wound healing. Colloids Surf B Biointerfaces. 2014;113:152-7.

\section{Publisher's Note}

Springer Nature remains neutral with regard to jurisdictional claims in published maps and institutional affiliations. 